\title{
De karakterisering van Electra: een taalkundige benadering
}

\author{
Evert van Emde Boas ${ }^{1}$
}

\section{Summary}

The aim of this article is to show that modern linguistic approaches may be used in the analysis of characterization in Greek tragedy, specifically that of Euripides' version of Electra in the eponymous play. I analyse several of Electra's interactions with other characters in the play's early scenes, applying insights from linguistic politeness theory and conversation analysis, in order to show that Electra's linguistic 'behaviour' is driven by her situation and her preoccupations. Her interactions with the Peasant and the Chorus are marked by consistent affection from all sides, but also by a fundamental inability to communicate effectively. In her long stichomythia with Orestes, disruptions of the conversational structure mark brief flares in Electra's language at moments where issues that particularly vex her are discussed.

\section{Inleiding: visies op Electra}

Wilamowitz noemde haar 'eine verdorbene Seele' (1883: 230); Kitto 'a woman in whom it is hardly possible to find a virtue' (19613: 333); Conacher, in zijn handboek over Euripides, een 'bitter, self-pitying, sharp-tongued virago' (1967: 205); een lemma in een recent encyclopedisch handboek beschrijft haar als 'a monomaniacal harridan' (Luschnig 2013). Electra, de hoofdpersoon van Euripides' gelijknamige tragedie, is onder geleerden bepaald niet de meest populaire figuur. Deze reeks citaten zou nog

\footnotetext{
${ }^{1}$ Dit artikel is een uitwerking van mijn lezing voor de VCN Nazomerconferentie op 16 september 2016. Ik spreek graag mijn dank uit aan de deelnemers van die bijeenkomst voor hun vragen en commentaar.
} 
eindeloos kunnen worden uitgebreid., maar er zijn ook tegengeluiden, ${ }^{2}$ niet in de minste plaats in het voortreffelijke commentaar van Cropp (1988, herziene uitgave 2013), dat ik in mijn onlangs in dit tijdschrift Lampas verschenen 'Signalement' (van Emde Boas 2016) al heb aangeprezen.

Dat soort tegengeluiden lijken er aan te hebben bijgedragen dat er in de besprekingen van het Electrapersonage in de eindexamenbundels van dit jaar verschillende nuances doorklinken. De beschrijving in de Eismabundel lijkt in enkele opzichten op die van Cropp en legt enige nadruk op Electra's grieven, die als reëel worden gepresenteerd:

Elektra heeft veel te verduren: haar moeder heeft haar vader gedood, de nieuwe man van haar moeder he[e]ft haar uitgehuwelijkt en verbannen naar het platteland, en ze voelt zich helemaal alleen omdat haar broer op de vlucht is. Elektra voelt een zeer grote affectie voor haar vader, die ze idealiseert; voor haar moeder en Aigisthos koestert ze een diepe haat ... Elektra is mede door haar rouw uiterst sterk en vastberaden; ze heeft een zwart-wit-kijk op de wereld die een jonge, bijna puberale geest verraadt. (Verheij et al. 2016a: 44)

In de Hermaionbundel ligt de nadruk anders: deze bespreking spitst zich toe op Electra's wraakzuchtige emoties en op haar neiging om doorlopend te klagen:

Euripides' Electra [wordt] gedreven door een allesoverheersende wraakzucht. De moord op haar bewonderde vader en de daarop volgende verwaarlozing door haar moeder hebben er voor gezorgd dat ze zich permanent een slachtoffer voelt. Ze klaagt doorlopend over haar ellendige lot ... Alleen het denken aan de

2 Ook anti-Electra, bijvoorbeeld: Stoessl (1956), O’Brien (1964), Arnott (1981), Yoon (2012: 74-77, 99-105). Voorstanders, of ten minste gematigd, bijvoorbeeld: Steidle (1968), Zeitlin (1970), Michelini (1987: 187-194), Ormand (2009). Electra's meest fervente verdediger is Lloyd (1986). 
wraak die ze met haar broer zal nemen, houdt haar overeind, lijkt het wel. (Artz et al. 2016: 167)

In dit artikel zal ik mijn eigen voorkeur voor de eerste van deze twee beschrijvingen — die mijns inziens overigens allebei zeer goed verdedigbaar zijn - toelichten. Het bredere doel van het artikel is echter om te laten zien hoe dit soort vraagstukken kunnen worden benaderd vanuit een wellicht onverwachte hoek: de taalkunde. Dat taalkundige benaderingen kunnen bijdragen aan literaire analyse is in Nederland (en in Lampas) gelukkig onomstreden, maar dat zij ook relevant kunnen zijn voor een behandeling van karakterisering in de tragedie (een bij uitstek letterkundig onderwerp) ligt misschien minder voor de hand. Toch lenen enkele subdisciplines binnen de taalkunde zich bijzonder goed voor een dergelijke kruisbestuiving: het gaat daarbij met name om benaderingen die zich toespitsen op sociale en interactieve aspecten van taalgebruik, bijvoorbeeld pragmatiek, sociolinguïstiek en conversatieanalyse.

Een belangrijke premisse bij de toepassing van dergelijke theorieën op de Electra is dat Euripides zijn personages niet alleen vormgeeft door wat hij ze laat zeggen en doen, maar ook hoe hij ze dat laat zeggen - bij wijze van spreken door hun 'talige gedrag'. Het is dat gedrag dat ik in dit artikel wil bekijken, waarbij ik mij vooral zal richten op de eerste paar scènes van het stuk (door Cropp omschreven als 'something of a test case in the discussion of characterization in Greek tragedy' (2013: 6), en daarmee ook geschikt als proef voor mijn taalkundige benadering). Ik behandel de interactie tussen Electra en haar eerste twee gesprekspartners, de boer en het koor, en vervolgens bespreek ik de lange stichomythie tussen Electra en Orestes (op dat punt nog niet als zodanig door zijn zus herkend). Beide behandelingen worden voorafgegaan door een korte inleiding op

\footnotetext{
${ }^{3}$ Dit is ook de centrale premisse van mijn boek over het stuk, Language and Character in Euripides' Electra (te verschijnen 1 jan.Van Emde Boas, 2017 b): dit artikel presenteert in verkorte vorm enkele van de daar uitgewerkte analyses.
} 
een bepaalde tak van sport binnen de taalkunde, respectievelijk de beleefdheidsleer beleefdheidstheorie en de conversatieanalyse. ${ }^{4}$

\section{Taalkundige benaderingen (i): beleefdheid en onbeleefdheid}

Handboeken over talige beleefdheid bestonden lang alleen in prescriptieve vorm: wat is de correcte manier om iemand aan te spreken, hoe moet men een bepaald soort verzoek doen, enzovoort. Sinds de jaren '70 van de vorige eeuw hebben descriptieve benaderingen van de beleefdheid binnen de sociologie en sociolinguïstiek echter een stormachtige ontwikkeling doorgemaakt. Van de vele verschillende modellen die zijn ontwikkeld is er één verreweg het meest invloedrijk: dat van Penelope Brown en Stephen Levinson. ${ }^{5}$ Het model is zeker niet probleemloos, ${ }^{6}$ maar kan — ook omdat het al

${ }^{4} \underline{\text { Ik geef in dit artikel, ook op verzoek van de redactie, de voorkeur aan het gebruik van }}$ de oorspronkelijke Engelse terminologie behorend bij deze twee benaderingen, hoewel er in Nederlandstalige handboeken (bijvoorbeeld Huls, 2001; Mazeland, 2003) Nederlandse equivalenten zijn ingevoerdVoor beide benaderingen bestam Nederlandstalige handboeken, zodat het mogelijk is om hieronder overal Nederlandse terminologie te gebruiken. Die Nederlandse equivalenten zijn vaak (nog) minder idiomatisch dan de Engelse termen, en Omdat de Engelse terminologiehet Engelse begrippenapparaat wordt universeel gebruikt is in de taalkundige vakliteratuur, geef ik enkele niet-transparante Engelse equivalenten tussen haakjes. Ik geef Nederlandse equivalenten wel tussen haakjes.:

${ }^{5}$ Oorspronkelijke presentatie van het model in Brown \& Levinson (1978), uitgewerkt in Brown \& Levinson (1987). Een Nederlandstalige presentatie in bijvoorbeeld Huls (2001). Het onderzoek naar onbeleefdheid is in opkomst: zie bijvoorbeeld Bousfield (2008), Culpeper (2011).

${ }^{6}$ Zie de kritieken in bijvoorbeeld Watts (2003), Kádár \& Haugh (2013).
Commented [AS2]: beleefdheidsleer klinkt een beetje als etiquette-onderwijs.

Commented [LL3]: Zie algemene opmerkingen; je uiteindelijke keuze heeft ook consequenteis voor hoe je deze voetnoot formuleert. 
eerder is gebruikt in onderzoek naar klassieke literatuur ${ }^{7}-$ hier toch goed als uitganspunt dienen.

Het sleutelbegrip van het Brown-Levinsonmodel is gezicht face (Engels: face'gezicht'; vergelijk 'gezichtsverlies'), ${ }^{8}$ te definiëren als het publieke imago dat gesprekspartners in hun interacties overeind willen houden. Brown en Levinson zien gezicht $\underline{\text { face }}$ als een tweeledige basisbehoefte (ik ontleen mijn formuleringen- $\underline{\text { definities }}$ aan Huls 2001: 16):

- Negatief gezichtNegative face ('negatief gezicht'): 'Enerzijds hebben mensen behoefte aan een eigen domein. Ze willen in hun vrijheid gerespecteerd worden en onafhankelijk zijn.'

- Positief gezichtPositive face ('positief gezicht'): 'Anderzijds kunnen ze zich in volledig isolement niet als mens ontplooien. Ze hebben ook behoefte aan sympathie en betrokkenheid. Ze willen aardig gevonden worden.

Gezicht-Het face van gesprekspartners staat in gesprekken (en andere vormen van interactie) en andere vormen van interactie-voortdurend onder druk. Het gevaar loert hier in zogenaamde gezichtsbedreigende handelingenface-threatening acts (Engels: face-threatening act, FTAFTA, 'gezichtsbedreigende handeling'). Het kan daarbij gaan om expliciete beledigingen, bedreigingen, verboden, enzovoort, maar ook om de meest alledaagse en op het oog ongevaarlijke taalhandelingen: iemand die zijn tafelgenoot vraagt het zout aan te geven, doet daarmee inbreuk op het negatieve gezichtnegative $\underline{\text { face }}$ van zijn/haarzijn gesprekspartner, die zijn/haarhaar eigen maaltijd moet
Commented [LL4]: eventueel Engesle term handhaven ? Hoewel deze het minst erg is ...., is 'face'; ook al bijna ingeburgerd in het Nederlands

Commented [LL5]: Als je de NLse term handhaaft, moet ere en bepaald lidwoord voor; bij zowel Engelse als NL term er enkele aanhalingstekens omheen zetten

Commented [LL6]: zie algemene opmerkingen

7 Zie bijvoorbeeld Lloyd (2004), Brown (2006), Scodel (2008) over de Ilias, Lloyd (2006), (2009), (2013), Catrambone (2016) over tragedie. Voor Latijn zie bijvoorbeeld Hall (2009).

8 Face als technische term werd door Brown en Levinson ontleend aan het werk van socioloog Erving Goffmann (1955). 
onderbreken. .9 Een student of leerling die tijdens een college of les een vraag stelt begeeft zich ook in een mijnenveld van gezichtsgevoelighedenface-gevoeligheden: de docent kan door de vraag wellicht de indruk krijgen dat zijhij/zij iets in eerste instantie niet goed heeft uitgelegd (een aantasting van zijn/haarhaar positief gezichtpositive face), en wordt daarnaast gedwongen zijn/haarhaar college onderbreken om op de vraag in te gaan (een inbreuk op negatief gezicht negative face); de student/leerling op zijn/haarzijn beurt kan de indruk wekken dat hij/zijhij traag is van begrip (een aantasting van het eigen positief gezichtpositive face). Dit laatste voorbeeld is in de praktijk natuurlijk meestal overdreven - docenten zien vragen over het algemeen niet als ongewenste onderbreking - en dat is daarmee meteen een voorbeeld van de contextgevoeligheid van gezichtsafwegingenface-afwegingen. Tegelijkertijd laat de terughoudendheid van sommige studenten en leerlingen, en de angst voor het stellen van 'domme vragen', zien dat dit soort overwegingen wel degelijk meespelen.

Talige beleefdheid is volgens Brown en Levinson altijd georiënteerd op een gezichtsbedreigende handeling,FTA en heeft als doel om de dreiging voor het gezicht van (met name) de hoorder zo veel mogelijk te neutraliseren of beperken. In het Brownen Levinson-model wordt onderscheid gemaakt tussen drie overkoepelende superstrategieën met dat doel (elk bestaand uit talloze substrategieën):

- Positieve beleefdheidPositive politeness, gericht op het ondersteunen van positief gezichtpositive face, dat wil zeggen het gebruik van solidariserende middelen: vriendschapstermen ("m'n bestemaat", "lieverdschatje”, enzovoort) uitdrukkingen van sympathie en bewondering ("jij bent hier heel goed in"), inclusiviteit, overeenstemming, enzovoort.

- Negatieve beleefdheidNegative politeness, gericht op het ondersteunen van negatief gezichtnegative face, dat wil zeggen het gebruik van respectvolle middelen: verontschuldigingen ("pardon"), uitdrukkingen van eerbied ("meneer",
Commented [LL7]: dit is niet zonder meer duidelijk; lezer denken bij FTA's gewoonlijk alleen/vooral aan bedreigingen van het egzicht van de ander!
Commented [LL9]: zie algemen opmerkingen: wat vind je van 'uitdrukingen van solidariteit'?

Commented [EvEB10R9]: dit is letterlijk Huls, dus misschien maar laten?

Commented [LL11]: misschien niet het ebste vb, heeft iets denigrerends (of erg ouderwets0

Commented [LL12]: het voorbeeld ('pardon') is negative politeness, maar de term 'respectvol' lijkt eerder te passen bij positieve beleefdheid ;

Commented [EvEB13R12]: ook letterlijk Huls

${ }^{9}$ Om overmatig gebruik van 'hij/zij' te vermijden wissel ik willekeurig tussen mannelijke en vrouwelijke denkbeeldige gesprekspartners. 
"u"), minimalisering van de FTA, conventionele indirectheid ("Kunt u het zout aangeven?" in plaats van "Geef het zout aan"), enzovoort.

- Indirecte beleefdheid (Engels: olff__record politeness_('indirecte beleefdheid'): indirecte en/of ambigue uitingen van de FTA, die de hoorder een 'ontsnappingsroute' (een out) geven ("Het is hier best koud", "Als die deur open staat tocht het hier altijd", bedoeld als verzoek om het raam dicht te doen).

Een laatste tweetal mogelijkheden is om de gezichtsbedreigende handelingFTA zonder enige vorm van omhaal (Engels: baldly) te doen, of om juist helemaal af te zien van de handelingFTA. Brown en Levinson beweren dat sprekers bij het inkleden van hun taalhandelingen een keuze maken tussen bepaalde beleefdheidsstrategieën volgens de in Figuur 1 weergegeven rangschikking, waarbij de keuze afhangt van een inschatting door de spreker van het gewicht van de gezichtsbedreigingface-dreiging:

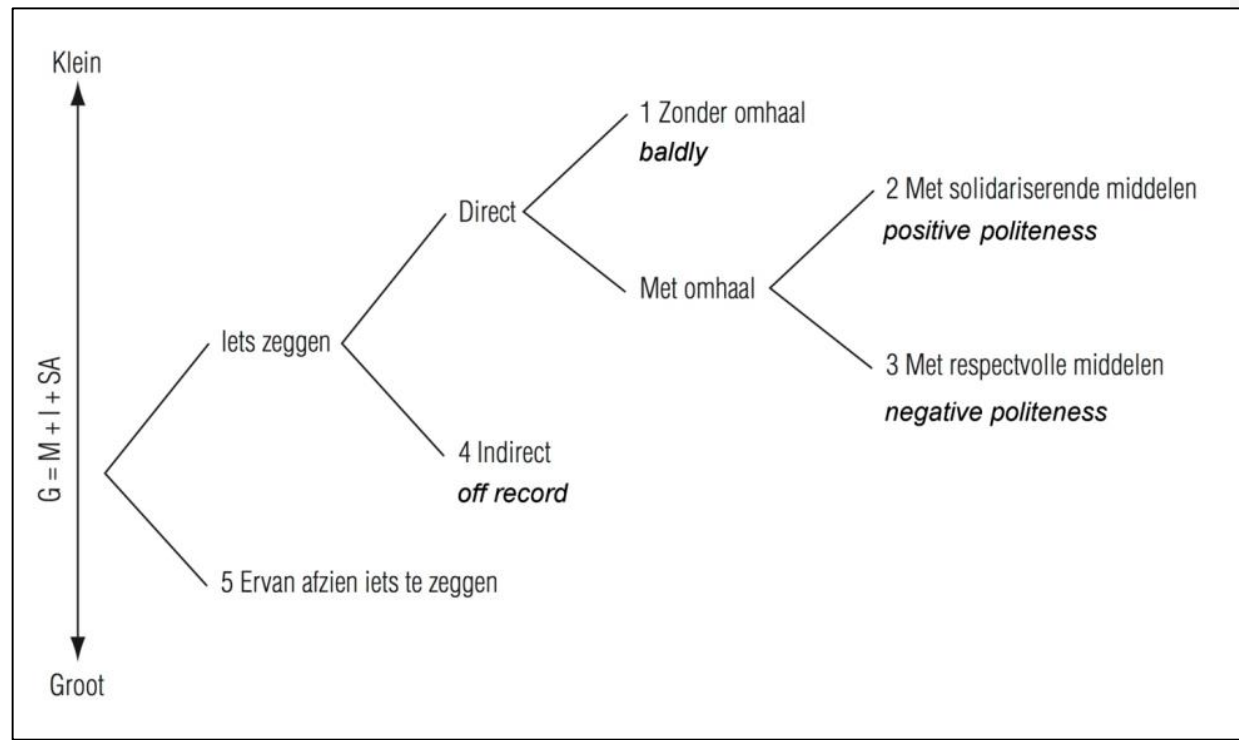

Figuur 1: Ordening van beleefdheidsstrategieën. Uit Huls (2001: 30), met Engelse termen toegevoegd;-op basis van Brown \& Levinson (1987: 60). G = gewicht van de gezichtsbedreiging; $M=$ machtsverhouding tussen spreker en hoorder; $I=$ inbreuk van de handeling op zich; SA = sociale afstand tussen spreker en hoorder. 
Er is, zoals boven al aangegeven, veel (en vaak terechte) kritiek geweest op het Brown en -Levinson-model..$^{10}$ Een centraal punt dat daarbij regelmatig wordt gemaakt is dat het idee dat het model universeel geldig is dat de claim van universele geldigheid $€=$

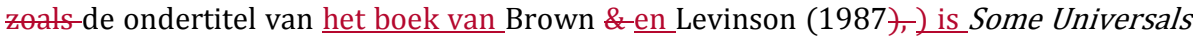
in Language Use, wil suggereren) _ in de praktijk niet klopt. We moeten dus voorzichtig zijn voordat we het model klakkeloos toepassen op literatuur die het product is van een cultuur die in tijd en wat betreft sociale conventies ver van ons af staat. Toch hoop ik te laten zien dat het benaderen van Electra's interactie met haar gesprekspartners met het oog op de gevoeligheden van 'gezicht'face en beleefdheidsstrategieën een zinvolle exercitie kan zijn.

\section{Toepassing (i): Electra, de boer-en het koor}

Commented [AS15]: Een Oxford-komma? Onmiddellijk na de openingsmonoloog van de boer verschijnt Electra op het toneel om haar lot te beklagen. Ze legt uit dat ze op weg is naar de rivier om water te halen. Daarna wordt het publiek getrakteerd op een milde echtelijke ruzie (54-78):11

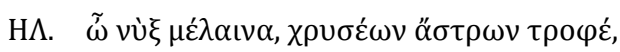

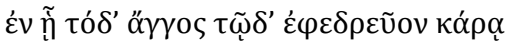
55

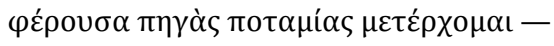

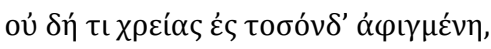

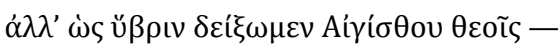

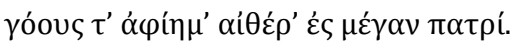

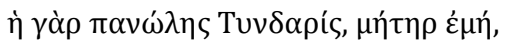

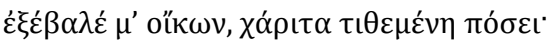

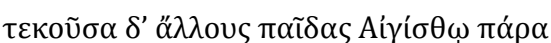

\footnotetext{
10 Zie vootnoot 6 boven.

11 Griekse teksten zijn overgenomen uit Cropp (2013), maar zie voetnoot 26 hieronder over $\underline{1107-1108 . \text { Vertalingen zijn van mijn hand. }}$
} 


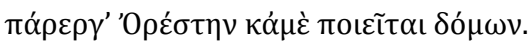

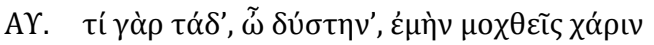

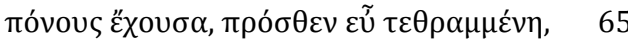

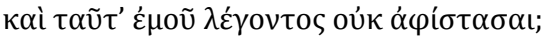

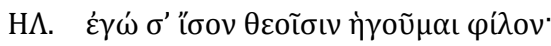

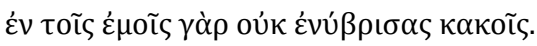

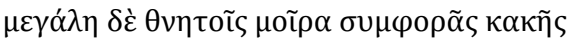

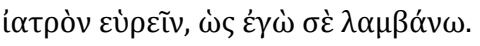

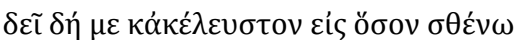

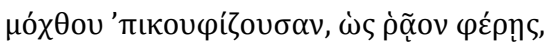

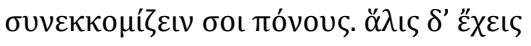

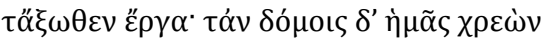

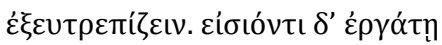

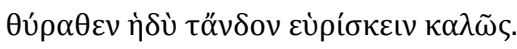

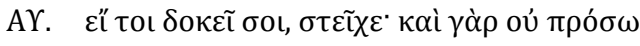

$\pi \eta \gamma \alpha \grave{\iota} \mu \varepsilon \lambda \alpha \dot{\theta} \theta \rho \omega \nu \tau \tilde{\omega} v \delta^{\prime}$.

Electra: Nacht, voedster van de gouden sterren, waarin ik met deze kan staand op mijn hoofd water ga halen uit de rivier - niet omdat ik zo behoeftig ben, maar om de brutaliteit van Aegisthus aan de goden te demonstreren - en klaagzangen voor mijn vader uitstort tot de wijdse hemel. Want mijn moeder, de verderflijke dochter van Tyndareus, heeft me verbannen uit het huis, als gunst aan haar echtgenoot. En door andere kinderen aan Aegisthus te baren berooft ze Orestes en mij van onze status in het paleis.

Boer: Waarom dan, arme vrouw, draag je deze last voor mij, ploeterend terwijl je van huis uit zo vooraanstaand bent opgevoed, en hou je niet op ook al vraag ik je dat te doen?

Electra: Ik beschouw je als gelijk aan de goden door je vriendschap. Want in mijn ellende heb je geen schandelijk gedrag vertoond. Het is een groot goed om een 
verzachter van een ellendig lot te vinden, zoals ik jou tref. Ik moet je dan ook, ook als je er niet om vraagt, helpen bij je werk voorzover ik dat kan, door je last te verlichten zodat jij hem makkelijker kunt dragen. Jij hebt al genoeg werk buitenshuis. Wat er binnen moet gebeuren is aan mij om te verzorgen. Voor een werkman is het aangenaam om wanneer hij thuiskomt de situatie binnenshuis in orde aan te treffen.

Boer: Nou, als jij het wil, ga dan maar. De rivier is ook niet zo ver van dit huis.

Wanneer we dit gesprek analyseren aan de hand van de in de vorige paragraaf geïntroduceerde theorie ${ }_{2}$ blijkt dat de beurt bijdrage van de boer in 64-66 een complexe functie vervult. Oppervlakkig gezien is wat hij zegt een vraag over naar Electra's redenen om water te halen ("Waarom draag je deze last voor mij?"); maar door de

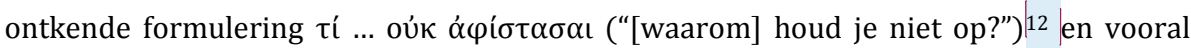
door de toegevoegde genitivus absolutus $\varepsilon$ ㅇõ $\lambda \dot{\varepsilon} \gamma o v \tau o \varsigma$ ("ook al vraag ik je dat") wordt duidelijk dat het in werkelijkheid om veel meer gaat dan een vraag. De boer bekritiseert Electra om haar waterexpeditie, ${ }^{13}$ en wil eigenlijk dat ze daar mee ophoudt. Dit is daarmee een gezichtsbedreigende handeling $\underline{F T A}$ voor Electra, die door de boer lijkt te worden berispt voor haar halsstarrigheid (een aanval op haar positief gezichtpositive $\underline{\text { face) }}$ en door hem wordt beperkt in haar bewegingsvrijheid (negatief gezicht $\underline{\text { negative }}$ face).

Maar hoewel de boer een duidelijke kritische noot aanbrengt, doet hij er ook alles aan om de gezichtsbedreiging face-dreiging van zijn beurtwat hij zegt te beperken. Ten eerste gebruikt hij om het positief gezichtpositive face van zijn vrouw te ondersteunen

12 De implicatie van dit soort negatieve vragen ("Waarom niet...?") is vaak dat de ontkende situatie de gewenste is: in dit geval dus dat Electra eigenlijk wel moet ophouden met water halen.

13 "His question is in fact a kind of gentle rebuke”, Bain (1977: 34). Zo ook bijvoorbeeld Mastronarde (1979: 27 n. 34). Denniston lijkt dit te missen in zijn commentaar: zie mijn bespreking hieronder. 


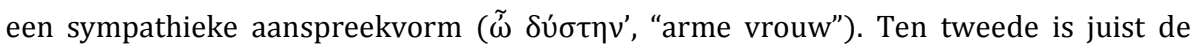
omslachtige formulering in de vorm van een vraag een middel om de face-dreiging gezichtsbedreiging voor Electra te minimaliseren. Dit is een klassiek voorbeeld van wat boven werd gedefinieerd als een 'indirecte' (off record) off record beleefdheidsstrategie: de boer zegt niet ronduit 'hou op', maar biedt Electra, door zijn kritiek-cum-verzoek te verpakken als vraag, een ontsnappingsroute (een out) - de mogelijkheid om de gezichtsbedreigende handeling $\underline{F T A}$ niet als zodanig op te vatten.

Electra's reactie (67-76) bedreigt op zijn beurt het gezicht face van de Boer (wiens verzoek/klacht niet wordt ingewilligd), maar is tegelijkertijd omkleed met uitvoerige allerlei positieve beleefdheidpositive politeness- en negatieve beleefdheidnegative politeness-strategieën: Electra begint met een uitgebreide lofprijzing van de boer (6770), en besteedt ook veel aandacht aan zijn bewegingsvrijheid (74-76). Het meest merkwaardige aan de hele dialoog is echter het feit dat; en hoede manier waaropElectra gebruik maakt van de entsnappingsroute out die de boer haar heeft geboden. Ze beantwoordt zijn 'vraag' (maar ten dele een vraag, zoals we hebben vastgesteld) met een echt antwoord, en licht toe dat ze zich genoodzaakt ziet tot water halen "zelfs

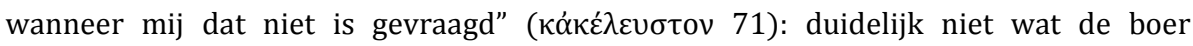
bedoelde met zijn $\varepsilon$ \&oũ $\lambda \varepsilon^{\prime} \gamma o v \tau o \varsigma$ in 66 !

Nog merkwaardiger wordt het wanneer we de door Electra gegeven motivatie vergelijken met haar eerdere woorden in 57-58. Daar beweerde Electra immers dat haar waterexpeditie bedoeld was om de hubris van Aegisthus aan de goden tentoon te

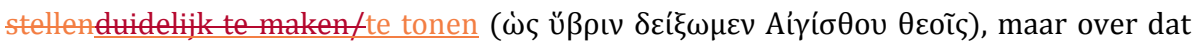
motief horen we in haar antwoord aan de boer niets meer. En: als de boer die eerdere woorden heeft gehoord, waarom 'vraagt' hij dan naar Electra's redenen? Voor sommige commentatoren en tekstbezorgers zijn dit onoverkomelijke inconsistenties: Kirchhoff en Wecklein delgden 57-59, terwijl Denniston in zijn commentaar (1939: ad 64-66) pleitte voor een opvallende enscenering: "Electra has given the answer herself at 57-9. But the Commented [LL21]
welke edities dit zijn 
solution."14 Maar deze oplossing - een tijdelijke evacuatie van de boer - lijkt geforceerd, en wordt mijns inziens weerlegd door het gebruik van het partikel $\gamma \alpha$ ó in 64, dat een signaal moet zijn dat de boer met zijn beurt woorden reageert op die van Electra, en die dus gehoord moet hebben..$^{15}$

In plaats van als een textueel of dramaturgisch 'probleem' kunnen we de schijnbare onwetendheid van de boer en de verschillende door Electra geboden motieven beter interpreteren als tekenend voor de manier waarop de communicatie tussen man en vrouw in deze scène spaak loopt. Cropps lezing brengt ons in de juiste richting (2013: ad 54-81):

The reasons [Electra] offers for her toil ... are not so much contradictory as on different levels: on one level her isolation in grief and humiliation, on the other her participation in a mundane life where the Peasant himself assumes that she toils 'for my sake' (64), just as the Chorus will expect her to share their activities.

14 De mogelijkheid van deze enscenering wordt in de Eismabundel ook voorgelegd aan leerlingen: "Volgens sommige commentaren kan de Boer Elektra's woorden niet gehoord hebben en is hij misschien even teruggegaan de boerderij in ... Hoe kun je de opmerking van de Boer verklaren als hij wel degelijk heeft gehoord wat Elektra zei?" (Verheij et al. 2016a: 59). Met de suggestie in het antwoordmodel - "Dan is het eigenlijk niet echt een vraag naar een reden, maar een (kennelijk herhaald) verzoek om op te houden met het werk" (Verheij et al. 2016b: 4) - ben ik het gezien mijn betoog boven helemaal eens, maar hij is zoals ik hieronder zal laten zien, mijns inziens nog geen echte 'verklaring'.

15 Het gebruik van $\gamma \alpha$ ó is, zoals Denniston zelf aangeeft (1939: ad loc.), "difficult", maar mijns inziens niet onverklaarbaar: het partikel laat zien dat de boer vraagt om een nadere toelichting bij Electra's voorgaande woorden. Voor een volledigere e bespreking verwijs ik naar van Emde Boas (te verschijnen-2017b: 72). Kun je jouw verklaring globaal aanduiden? Hoewel het boek al uit is als deze Lampas in februari verschijnt, zullen docenten het niet in de kast heben staan .. 
Wat vooral opvalt is dat de boer in deze scène 'toegang' heeft tot slechts één van de twee door Cropp genoemde niveaus. Hij heeft wel gehoord wat Electra zegt, maar kan haar gedrag alleen interpreteren (en bekritiseren) vanuit zijn eigen, alledaagse perspectief. Electra, op haar beurt, beperkt zich in haar antwoord ook tot dat niveau, maar negeert daarbij ook de impliciete kritiek van haar man.

Wat leert taalkundige beleefdheidstheorie ons hier? Allereerst dat Electra en haar echtgenoot in hun interactie allebei hun uiterste best doen om elkaars gezicht face geen schade toe te brengen - lezingen die hameren op een onheuse bejegening van de boer door Electra slaan mijns inziens de plank mis. ${ }^{16}$ Anderzijds zien we hoe Electra, door de merkwaardige manier waarop ze gebruik maakt van de indirecte beleefdheidoff recordbeleefdheid van haar man (dat wil zeggen van de door hem geboden out), zich eigenlijk onttrekt aan zijn kritiek. Man en vrouw tonen grote affectie voor elkaar, maar van echt wederzijds begrip, van echt geslaagde communicatie, is geen sprake.

In dit opzicht vindt het gesprek tussen Electra en de boer een regelrechte parallel in de parodos, waarin Electra opnieuw een vermaning negeert, ditmaal van het koor (171200):

XO.

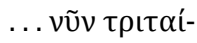

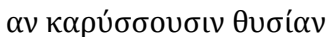

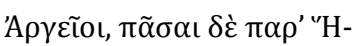

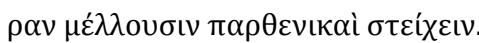

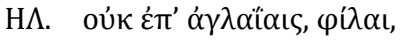

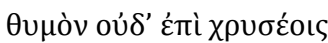

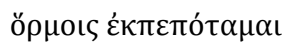

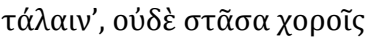

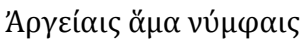

16 Zoals die van Arnott (1981). De oprechtheid van Electra's waardering voor de boer wordt gegarandeerd door haar gesprek met Orestes in 246-261; in 404-408 is Electra wel enigszins kortaf tegen de boer. 


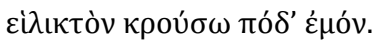

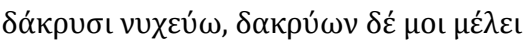

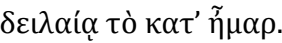

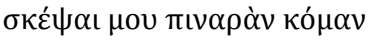

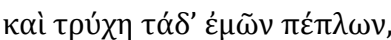

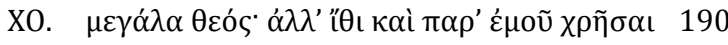

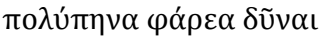

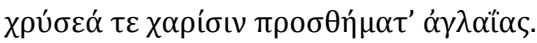

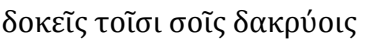

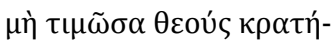

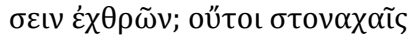

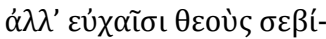

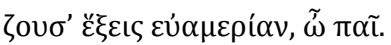

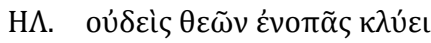

$\tau \tilde{\alpha} \varsigma \delta v \sigma \delta \alpha i ́ \mu o v o \varsigma$, ov́ $\pi \alpha \lambda \alpha \mathrm{L}-$

$\tilde{\omega} \nu \pi \alpha \tau \rho \grave{\varsigma} \varsigma \varphi \rho \alpha \gamma \iota \alpha \sigma \mu \tilde{\omega} \nu$.

Koor: ... de Argivers kondigen voor overmorgen een offerfeest aan, en alle meisjes zijn van plan naar het heiligdom van Hera te gaan.

Electra: Mijn hart, vriendinnen, raakt niet in vervulling voor schittering, of voor gouden kettingen, arme ik, en ik zal niet samen met Argos' bruiden in koren mijn voet draaiend stampen. In tranen breng ik de nacht door, aan tranen wijd ik, ongelukkig, ook mijn dagen. Kijk naar mijn vieze haar, en naar mijn vodden als kleren ...

Ko. De godin is machtig. Kom, leen toch van mij een fijn geweven mantel en trek hem aan, en gouden sieraden die schittering versieren. Denk je dat je met je tranen je vijanden zal verslaan, als je de goden niet vereert? Niet door kreunen, 
niet door klagen, maar door de goden met gebeden te eren zul je voorspoed vinden, mijn kind.

El. Geen van de goden luistert naar de stem van het ellendige kind, of de vroegere offers van vader.

De verzen 173-174 zijn een (indirecte) uitnodiging door het koor, die door Electra Commented [AS24]: Niet mooi om een zin met cijfers te beginnen. wordt afgewezen (175-189). De inherente gezichtsbedreiging-face-dreiging van die afwijzing wordt door Electra ingedamd door middel van-positieve beleefdheid (in de

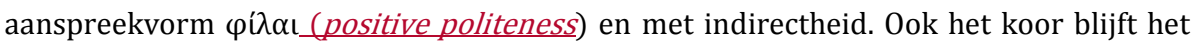
gezicht face van Electra ondersteunen, zelfs wanneer ze kritiek leveren op haar gedrag (193-197): zie bijvoorbeeld de door de vrouwen gebruikte familiaire aanspreekvorm $\tilde{\omega}$ $\pi \alpha \tilde{\mathrm{L}},{ }^{17}$ de manier waarop zij hun kritiek gieten in de vorm van een vraag ("denk je ... ?"),

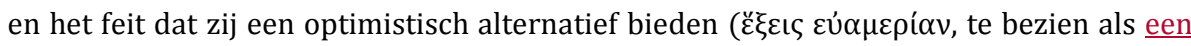
positieve beleefdheidpositive politeness-strategie).

De beleefdheidstheorieleef suggereert hier opnieuw dat Electra en haar gesprekspartner op omslachtige en welwillende manier met elkaar omgaan. Maar ook in deze interactie gaat de wederzijdse affectie niet gepaard met daadwerkelijk wederzijds begrip. Electra verzet zich tegen de pogingen van het koor om haar te doen ophouden met haar vertoon van rouw, net zoals ze zich verzette tegen vergelijkbare pogingen van de boer. De vrouwen van het koor, op hun beurt, vertonen net als de boer een ernstig gebrek aan inzicht in Electra's drijfveren: hoewel zij duidelijk heeft gemaakt dat ze niets

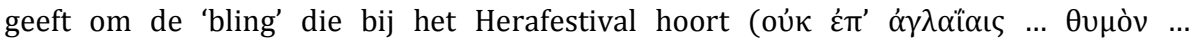

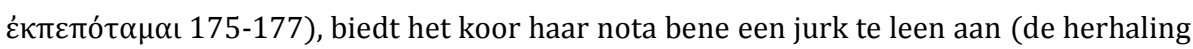
van het sleutelwoord $\alpha \gamma \lambda \alpha$ ii $\alpha$ in 192 is significant). “As if that [het gebrek aan een jurk]

17 De aanspreekvorm is in de tragedie altijd vriendelijk van toon, maar heeft ook regelmatig een connotatie van milde superioriteit: (m.n.) oudere sprekers gebruiken hem om jongere hoorders te overtuigen. Van een aanzienlijk leeftijdsverschil tussen koor en Electra is echter geen sprake (vergelijk vers 761, en zie Zeitlin 1970: 645 n.1): $\tilde{\omega}$ $\pi \alpha \tilde{i}$ lijkt dus retorisch gebruikt door het koor, als overtuigingsmiddel. 
was the real trouble!", roept Grube terecht uit (1941: 301). Dat het koor denkt met deze praktische oplossing iets voor elkaar te krijgen getuigt van dezelfde combinatie van welwillendheid en gebrek aan inzicht die we eerder aantroffen bij de boer.

De meest gangbare lezing van de scènes tussen Electra en de boer en Electra en het koor is er een van hypocrisie en overdreven zelfmedelijden:

Electra's complaint about carrying water ( $55 \mathrm{ff}$.) is immediately shown up by her gentle peasant-husband who says, first, that he has told her not to do it (64-66), and second, that it's a very slight labour in any case (77-78). Electra's complaint of lack of raiment for the feast to which the Chorus bids her is immediately shown up by her refusal of glorious clothes the Chorus offers. In both cases, it is the chance of self-martyrdom which Electra is seizing, and besides (as the Chorus observes of Electra's refusal) Electra would rather moan than pray (193-

95). (Conacher 1967: 205)

Maar deze lezing mist zowel de wederzijdse affectie tussen de karakters als de mate waarin de boer en het koor ten prooi vallen aan onbegrip. Electra haalt water en draagt haar vodden niet uit noodzaak (zoals ze zelf zegt, 57), maar als uiterlijke tekenen van rouw en als aanklacht tegen onrecht - een uiterlijk vertoon dat volgens Griekse normen waarschijnlijk overigens volledig op zijn plaats was. ${ }^{18}$ Maar de boer en het koor kunnen niet goed 'bij' Electra's rouw: zij opereren uitsluitend in de simpele, mondaine alledaagse wereld waar Electra noodgedwongen deel van uitmaakt. Daarbij komt dat de boer en het koor min of meer symbool staan voor Electra's ongeluk: haar armoedige faux-echtgenoot vertegenwoordigt haar statusverlies, ballingschap; en het verloren huwelijk met Castor dat ze eigenlijk had moeten hebben (zie 249, 312-313); de leden van het koor - ongehuwde vrouwen ( $\pi \alpha \rho \theta \varepsilon v \iota \kappa \alpha i ́$ 174) op weg naar een festival dat voor een getrouwde (maar nog steeds maagdelijke) vrouw eigenlijk niet geschikt was -

18 Zie hiervoor Steidle (1968: 67), Lloyd (1986: 3), Michelini (1987: 188).

Commented [AS25]: , mondain heeft volgens mij in het Nederlands een andere connotatie: 'werelds'. 'luxueus', sophisticated. Dat is toch hier juist niet de bedoeling? 
onderstrepen Electra's paradoxale huwelijkse status. ${ }^{19}$ Dit zijn onmogelijke omstandigheden, en de communicatieve dwalingen in deze eerste scènes zijn daarvan een exponent - de taalkundige onderstreping van haar isolement.

Voor de duidelijkheid: het betoog tot dusver is niet bedoeld om Electra te rehabiliteren als 'sympathiek' personage, ${ }^{20}$ maar om te wijzen op haar paradoxale situate situatie in de vroege scènes van het stuk - omringd door welwillende maar tot op zekere hoogte argeloze gesprekspartners. Electra's isolement kwelt haar; en is daarmee een cruciaal ingrediënt van haar haat voor haar moeder en Aegisthus. De bodem voor de moedermoord is gelegd. Deze aspecten van Electra's karakterisering de haat voor Clytaemestra en Aegisthus, de kwelling van haar isolement — bepalen haar 'talige gedrag' gedurende het hele stuk. Ook in de lange stichomythie tussen Electra en haar (vermomde) broer, mijn laatste passage, komen deze kenmerken terug. Voordat ik die bespreek introduceer ik eerst nog een taalkundige benadering, de conversatieanalyse.

\section{Taalkundige benaderingen (ii): conversatieanalyse}

Net als de beleefdheidsleer heeft de taalkundige conversatieanalyse (CA) van oorsprong sterke banden met de sociologie. De discipline werd aanvankelijk ontwikkeld door de Amerikaanse socioloog Harvey Sacks; in samenwerking met enkele studenten, die Sacks'

${ }^{19}$ Zie voor dit belangrijke aspect - Electra's 'painfully anomalous status as a virginal matron' (Michelini 1987: 192) - de discussie in Swift (2010: 189-190) en vooral Zeitlin (1970: 650). Ook Lardinois (2017) bepreekt dit punt in zijn artikel, elders in dit Lampas-nummer.

20 Zoals Lloyd poogt te doen (Electra is volgens hem 'plausible and sympathetic', 1986: 19) 
werk voortzetten na diens vroegtijdige dood. ${ }^{21}$ Hun methodologie was empirisch: aan de hand van opnames en transcripties van echte gesprekken werden patronen geïdentificeerd en geanalyseerd, om zo te beschrijven hoe gespreksdeelnemers hun interactie organiseren en begrijpelijk maken. De $\mathrm{CA}_{\text {conversatieanalyse houdt zich bezig }}$ met allerlei aspecten, zoals de manieren waarop sprekers aan beurtwisseling doensprekerswisseling, manieren waarop ze-sprekers een gespreksonderwerp (topic) aankondigen of veranderen, en de manieren waarop sprekers gecoördineerd interactionele activiteiten uitvoerenhun bijdragen aan het gesprek op elkaar afstemmen. In dit artikel beperk ik mij tot een bespreking van-dat laatste aspect, het verschijnsel van sequentieorganisatiesequence organization ('sequentie-organisatie').:

Sequenties-Een sequence ('sequentie') is eenzijn samenhangende spreekbeurten reeks gespreksbijdragen (turns, 'beurten') waarmee sprekers een bepaalde taalhandeling (informatie uitwisselen, standpunten innemen, een afspraak maken, enzovoort) uitvoeren. Dit soort sequenties zijn onderhevig aan bepaalde structurerende principes_dat wil zeggen aan-_(sequentie_organisatiesequence organization): het meestDe meest fundamentele vorm, en het basisprincipe, van sequentie-organisatie is fundamentele van die principes, de basisvorm van gesprekken, is het aangrenzende paaradjacency pair (Engels: adjacency paif'aangrenzend paar'). Door een bepaald type eerste deelfirst pair part ('eerste paardeel') van een aangrenzend paafadjacency pair eerste paardeel (pair part) te doen zet een spreker een bepaalde project op de agenda, en activeert daarmee een redelijk dwingende verwachting voor een bepaald type

21 De eerste sleutelpublicatie was Sacks et al. (1974). Sacks' lezingen zijn verzameld in Jefferson (1992). Belangrijke handboeken zijn Schegloff (2007), Sidnell \& Stivers (2012). Een geslaagde Nederlandstalige inleiding is die van Mazeland (2003); ik geef hieronder haar Nederlandse terminologie tussen haakjes. CA-Conversatieanalyse werd nog nauwelijkstot voor kort weinig op de klassieke literatuur toegepast, maar zie Slings 1997? (heeft het ook over sequenties): impliciet werd hij gebruikt door Slings (1997). explicieter; door Smith (2012), Schuren (2014: hst. 1), Barrios-Lech (2016), Bonifazi et al. (2016), van-Van Emde Boas (te verschijnen-2017a).
Commented [LL26]: liever overal voluit

Commented [LL27]: duidelijk zonder toelichting ? eventueel de hele clause samenvatten als "sprekerswisseling'

Commented [LL28]: nogal formeel en misschien niet zonde meer duidelijk; wat vind je van een lossere omschrijving zolas "hu bijdragen aan het gesprek op elkaar afstemmen"?

Commented [LL29]: 'spreekbeurten'heeft op middelbare scholen, ook voor docenten. de verkeerde connotatie'; wat vind je van de volgende omschrijving, waarmee je meteen de term 'beurt' definieert

"een samenhangende serie van gespreksbijdragen ('beurten') “?

Commented [AS30]: bij klinkerbotsing is een streepje verplich

Commented [LL31]: en dan eventueel een voetnoet met de Engelse term plus de "officiële (doch vreselijk) vertaling "paardeel") - zie algemene opmekringen 
tweede paardeelsecond pair part ('tweede paardeel'), dat dat project voltooit. Hier zijn twee voorbeelden van typische aangrenzende parenadjacency pairs, vraag-antwoord en uitnodiging-aanvaarding:

Jan: Hoe laat is het?

VRAAG - eerste paardeelfirst pair part

Joke: Drie uur. ANTWOORD - second pair partweede

paardeel

Jan: Heb je zin om mee uit eten te gaan?

UITNODIGING - first pair parteerste paardeel

Joke: Ja graag. AANVAARDING - second pair parttweede

paardeel

Er-Gewoonlijk zijn er meestal verschillende tweede paardelensecond parts mogelijk om een eerste paardeelfirst part te completeren ${ }_{\llcorner}$- (behalve in geheel symmetrische aangrenzende paren zoals groet-groet); maar deze verschillende mogelijkheden zijn niet allemaal gelijkwaardig._- Over - Voor de meeste soorten typentypes van angrenzende parenadjacency pair is een zogenaamde preferentieorganisatiepreference organization ('preferentie-organisatie') van kracht, waarbij één soort second part tweede paardeel — normaal gesproken dat het soort-paartweede deel dat tot projectsucces leidt — geldt als geprefereerdpreferred ('geprefereerd'), en andere soorten als gedisprefereerddispreferred ('gedisprefereerd'). Het $\underline{\text { In het hierboven }}$ gegeven voorbeeld van een uitnodiging-aanvaarding heeft bijvoorbeeld een-zien we heteen geprefereerde preferred second part soort tweede paarddeel_(aanvaardiging)en-i een miet pregrefereerd deeddispreferred second part is bijvoorbeeld de -afwijzing- zoalsdie we vindenzien in: kan worden gecontrasteerd met het volgende voorbeeld:

Jan: Heb je zin om mee uit eten te gaan? UITNODIGING

Joke: Nou, ehm, ik heb nogal veel werk. —AFWIJZING — gedisprefereerd
Commented [LL32]: dit weglaten; hier niet relevant en onderbreekt de uitleg

Commented [AS33]: Dat is geen Nederlands woord. Beter: 'nietgeprefereerd (Eng. 'dispreferred')'?

PASSIM

Commented [EvEB34]: inderdaad echt verschrikkelijk en geen Nederlands, maar wel de term die Mazeland gebruikt 
'Preferentie'Preference is hier overigens bedoeld als een structureel, niet een psychologisch principe: het gaat om de eigenschappen van de gespreksorganisatie, niet om de persoonlijke voorkeuren van de sprekers. Typerend voor gedisprefereerde dispreferred beurten-gespreksbijdragen is dat ze veelal gepaard gaan met omhaal, uitstel, extra toelichting, enzovoort (zie in het voorbeeld hierboven 'Nou, ehm, ...').

Het verschijnsel van preferentie-organisatiepreference organization maakt inzichtelijk waarom aangrenzende parenadjacency pairs regelmatig niet letterlijk 'aangrenzend' zijn, of waarom sprekers soms al vooruitlopen op een paar pair of dat na de klaarblijkelijke afronding ervan nog uitrekken. Het gaat hier om zogenaamde sequentie-expansiesexpansions ('expansies'), meestal dikwijls zelf in de vorm van sequentieseen adjacency pair, die een uitbreiding vormen op een basispaarbase pair ('basispaar'). Expansies bestaan in drie vormenEr bestaan drie typessoorten expansiesexpansion:

Pre-expansies Pre-expansions ('pre-expansies'):

Jan: Heb je al plannen voor vanavond? VRAAG (preexpansiepre-expansion)

Joke: Nee, hoezo? ANTWOORD

(pre-expansionpre-expansie)

Jan: Zin om uit eten te gaan?

UITNODIGING

(basispaarbase pair)

Joke: Ja, lijkt me leuk.

AANVAARDING

( base pairbasispaar)

Insertie_expansiesexpansions ('insertie-expansies'):

Jan: Zin om uit eten te gaan?

Joke: Hoe laat gaan jullie?

expansieinsert expansion)

Jan: Half acht.

expansioninsertie-expansie)

Joke: Perfect, leuk, ik ga mee.
ANTWOORD

UITNODIGING

VRAAG

(insertie-

(insert

AANVAARDING

(base pairbasispaar) 
PostexpansiesPost-expansions ('postexpansies'):

Jan: Zin om naar de film te gaan?

UITNODIGING

Joke: Ik ben gisteren al geweest, sorry. WEIGERING

Jan: Weet je het zeker?

VRAAG

\section{(postexpansiepost-expansion)}

Joke: Nou, vooruit, ik ga mee. ANTW./AANVAARDING (postexpansie)

In elk van deze voorbeelden is de expansie expansion erop gericht om projectsucces te bevorderen en gedisprefereerde dispreferred second parts tweede paardelen te vermijden:르 met de pre-expansiepre-expansion ("al plannen?") verzekert Jan zich ervan dat een aanvaarding van zijn uitnodiging üuberhaupt tot de mogelijkheden behoort; met de insertie-expansieinsert expansion ("hoe laat?") vraagt Joke op vergelijkbare wijze om nadere informatie die een geprefereerd antwoordpreferred antwoord mogelijk maakt; en de postexpansie post-expansion ("weet je het zeker?") heropent het basispaar base pair om een gedisprefereerd paardispreferred second part te laten herzien. ${ }^{23}$

Aangezien de CAconversatieanalyse zich toelegt op het bestuderen van gesprekken die 'in het wild' voorkomen, lijkt het niet vanzelfsprekend dat deze methodologie toepasbaar is op dramatische dialogen, zeker als het gaat om de sterk gestileerde dialogen van de Griekse tragedie, en al helemaal wanneer formele kenmerken als stichomythie natuurlijkheid in de weg lijken te staan. Maar de onnatuurlijkheid van tragische conversatie is relatief: dergelijke dialogen zijn in ieder geval gevormd volgens

22 We kunnen hier een brug slaan naar de beleefdheidstheorie: dispreferred second parts zijn vaak meteen ook face-threatening acts. De pre-expansion in het voorbeeld beperkt eventuele face-dreiging bij voorbaat: een mogelijke afwijzing van de uitnodiging zou gezichtsverlies betekenen voor beide gesprekspartners.

23 Daarnaast zijn Eexpansiesexpansions zijn-ook regelmatig gericht op herstel-repair (Eng, repaif herstel'), een gangbare activiteit in gesprekken waarbij gesprekspartners de lopende interactie even opschorten om een probleem (bijvoorbeeld bij het begrijpen of verstaan van een beurt) te verhelpen.
Commented [LL35]: is m.i. geen antwoord, alleen aanvaarding.

Commented [AS36]: Deze technische term is onnodig.en niet zo mooi.

Commented [LL37]: Hier een bruggetje naar het eerste deel "van het artikel maken, door iets als "on gezichtsverlies bij een eventuele afwijzing te voorkomen" en/of "om de hoorder een 'gezichtsbedreigende' weigering te besparen " 
het 'sjabloon' van echte gesprekken, en maken gebruik van dezelfde onderliggende structuren zoals beurtwisseling en samenhang in sequenties. ${ }^{24}$ En wanneer we stichomythie analyseren aan de hand van structuren zoals het aangrenzend paaradjacency pair preferentie-organisatiepreference organization; in sequentie expansiesexpansion, kan dat veel inzichtelijk maken over de toon en het verloop van gesprekken, plekken waar zulke gesprekken de mist in lijken te gaan, en - in het verlengde daarvan - de preoccupaties van de sprekers. Dit laat zich wellicht het best aantonen aan de hand van een tamelijk 'eenvoudig' voorbeeld uit de Electra. In 11231132 lokt Electra haar moeder Clytaemestra het huis in met het verzoek om een offer te volbrengen voor haar gefingeerde kind:

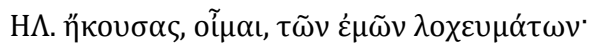

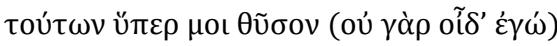

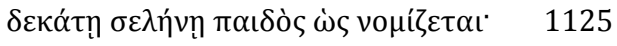

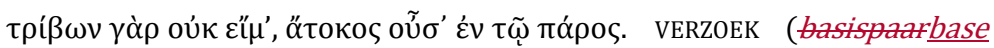
pair)

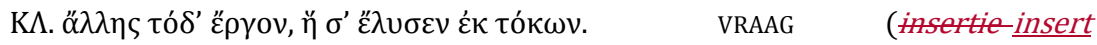
exp.1)

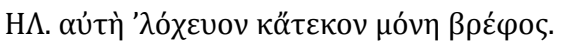
ANTWOORD (insertie-insert exp.1)

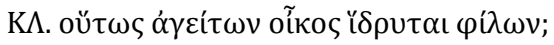
VRAAG (insert exp. insertie-2) 25

${ }^{24}$ Voor vergelijkbare argumenten, zie Herman (1995: 6; over drama in het algemeen) en Schuren (2014: hst.hoofdstuk 1; over Griekse tragedie).

25 1129-1130 zijn wellicht beter te bezien als een post_expansiepost-expansion bij 11271128, in plaats van als een zelfstandige insertie-expansieinsert expansion bij het basispaafbase pair. Dit soort recursie (expansies expansions van expansiesexpansions) is in natuurlijke gesprekken zeer gangbaar. 


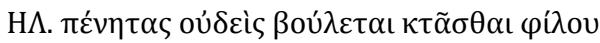

1130

ANTWOORD

(insert exp. insertie 2 )

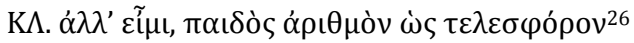

INWILLIGING (basispaarbase

pair)

$\theta \dot{\sigma} \sigma \omega \theta \varepsilon o \tilde{\sigma}$ เ....

El. U heeft meen ik gehoord over mijn bevalling. Voltrek daarvoor alstublieft een tiende-nacht-offer voor het kind, volgens gebruik: ik weet niet hoe dat moet. Want ik ben onervaren, aangezien ik hiervoor nog geen kinderen heb gehad.

Cl. Dat hoort iemand anders te doen, degene die je als vroedvrouw heeft begeleid.

El. Ik heb zelf mijn bevalling verzorgd, en in mijn eentje mijn kind gebaard.

Cl. Ontbeert dit huis dan zozeer bevriende buren?

El. Niemand wil arme mensen als vrienden.

Cl. Goed dan, ik ga, om het vereiste offer aan de goden te brengen voor het kind.

In antwoord op Electra's verzoek geeft Clytemnestra niet meteen haar akkoord, maar opent ze een reeks insertie-expansiesinsert expansions die bezwaren tegen de uitvoering van het verzoek aan de orde stellen. Clytaemestra's bezwaar in 112727 zouden we zelfs kunnen beschouwen als pre-afwijzing,pre-rejection ('pre-afwijzing'), een specifiek soort insertie insert expansion die-dat de voorbode vormt op een afwijzing zodat die (gedisprefereerde)-afwijzing (een dispreferred second part) -zelf niet expliciet hoeft te worden uitgesproken. ${ }^{28}$ Uiteindelijk gaat Clytaemestra wel overstag , en geeft zij

$26 \mathrm{Ik}$ ben het niet eens met de gangbare transpositie van 1107-1108 tussen 1130 en 1131: voor details verwijs ik naar van Emde Boas (te verschijnen 2017b: 151). Voor mijn betoog hier is deze kwestie niet van groot belang.

27 Door mij 'gecodeerd' als vraag, hoewel hij dat letterlijk natuurlijk niet is. De codering is gebaseerd op de gedachte dat Clytaemestra met haar beurt wel degelijk informatie van Electra wil krijgen.

28 Voor pre-afwijzingenpre-rejections, zie Schegloff (2007: 102-4). 
haar (geprefereerde) -instemming (preferred). ${ }^{29}$ Maar de complexe gespreksstructuur hier zegt veel over hoe Clytaemestra tegenover Electra's verzoek staat: haar $\underline{\text { het }}$ geprefereerde preferred antwoord was bij lange na niet vanzelfsprekend. Op een hoger niveau dienen de expansies natuurlijk ook als een vertragend middel, dat de spanning en de dramatische ironie van de scène sterk verhoogt.

Zoals dit voorbeeld laat zien zijn sequentie-expansiesexpansions in de Griekse tragedie vaak significant. Ter afsluiting, en om terug te keren naar de karakerisering van Electra, beschouw ik een tweetal plaatsen waar dergelijke expansies expansions door haar worden geïnitieerd onneer op het moment dat- het verloop van het gesprek met de vermomde Orestes haar niet lijkt te zinnen.

\section{Toepassing (ii): Electra en de 'vreemdeling'}

Het stichomythie-gesprek tussen Electra en haar vermomde broer in 215-289 is een voorbeeld van een gangbaar type in Euripides, de ondervraging,30 waarin Orestes informatie inwint over Electra's situatie. In feite gaat het om twee ondervragingen: vanaf het moment dat Electra is gerustgesteld dat de 'vreemdeling' geen kwade bedoelingen heeft (228), heeft zij eerst zelf het initiatief in het gesprek (dat wil zeggen, zij initieert aangrenzende parenadjacency pairs); en stelt ze een korte reeks vragen over de toestand van Orestes (229-236). Daarna blijft het initiatief voor de rest van de stichomythie bij de vreemdeling, die verschillende aspecten van Electra's toestand

${ }^{29}$ Clytaemestra's gebruik van het partikel $\alpha \lambda \lambda \alpha \dot{\alpha}$ in 1131 suggereert dat ze niet tevreden is met Electra's antwoorden: het partikel breekt de reeks expansies-expansions af (vergelijk Slings' (1997) beschrijving van ó $\lambda \lambda \alpha$ á als POP partikel) en impliceert daarmee in deze context dat die reeks eigenlijk niet naar bevrediging was afgerond.

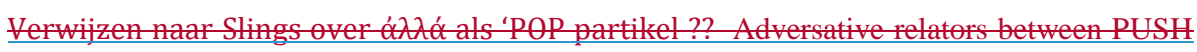
and POP. A. Rijksbaron (ed.), New Approaches to Greek Particles. Amsterdam 1997, p. 101129. Moet de sequentie overigens per se onbevredigend zijn-om afgebroken te worden doør Q́xגá als 'POP partikel'

${ }^{30}$ Voor dit type stichomythie, zie Schwinge (1968). 
bevraagt (238-289). Beide delen verlopen in grote lijnen in simpele aangrenzende adjacency pairs van het type vraag-antwoordparen,31 maar de overgang tussen de twee ondervragingen gaat, wat conversationele structuur betreft, met enig horten en stoten (237-243):

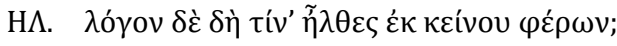

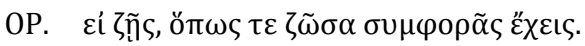

VRAAG (basispazrabase pair)

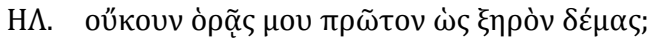
(insertie insert exp.1)

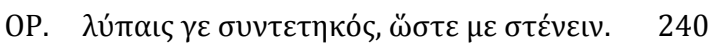
(insert exp. insertie-1)

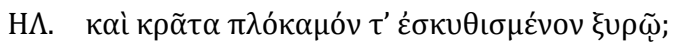
(insert exp. insertie-2)

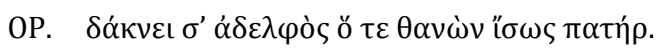
(insert exp. insertie-2)

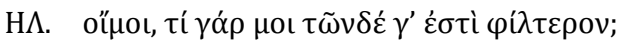

El. En welk bericht brengt u dan van hem?

Or. Hij wil weten of u leeft, en zo_ja, in wat voor toestand.

El. Ziet $\mathrm{u}$ dan niet hoe uitgeteerd mijn lichaam is?

Or. Ja, verweerd door leed: het grijpt me aan.

El. En hoe mijn hoofdhaar is geschoren?

Or. Het lot van uw broer en de dood van uw vader kwellen u wellicht.

El. Ach! Inderdaad, want wat is mij liever dan zij?

${ }^{31}$ Er treden op meerdere momenten afwijkingen in die structuur op. Er is hier geen ruimte om alle expansies in detail te bespreken, maar ik wijs nog wel specifiek op de door Orestes geïnitieerde postexpansies in 262-263 en 282-283, cruciale momenten in de dialoog waar Orestes zijn emoties nauwelijks in bedwang lijkt te kunnen houden en zijn identiteit bijna verraadt. 


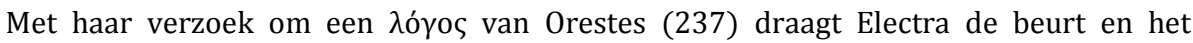
initiatief in het gesprek over aan de vreemdeling, die daarvan niet gebruik maakt om een

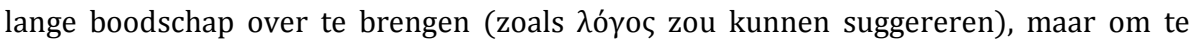
vragen naar Electra's situatie (238). Electra's reactie is veelzeggend: in plaats van een sobere expositie van haar leed opent ze zelf weer een sequentie met een (retorische) wedervraag - "ziet u niet ...?".32 De suggestie is dat de vraag van de vreemdeling onnodig was: Electra's uiterlijk zou alles al duidelijk moeten hebben gemaakt. Dat Electra hier, op het moment dat haar eigen toestand aan de orde komt, ingrijpt in de conversationele structuur ${ }_{\overline{3}}^{33}$ en signaleert hoe onbevredigend het door de vreemdeling uitgesproken eerste paardeelfirst part is, is significant voor haar karakterisering. Electra's situatie prikkelt haar,_en ontlokt in haar een momentane flits van ergernis.

We zien even later iets vergelijkbaars gebeuren in 274-275, wanneer de vreemdeling vraagt hoe Orestes met de situatie moet omgaan:

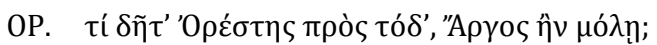
(eerste paardeel basispaarbase pair, first part)

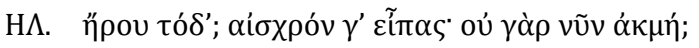

(insertie insert exp.+

Eveede

paardeelsecond partbasispaar)

Or. Wat moet Orestes hier dan aan doen, als hij naar Argos komt?

El. Vraagt $\mathrm{u}$ dat? Een schandelijke vraag: is nu niet het moment?

32 ои̋коuv/oúк ò $\rho \tilde{\alpha} \varsigma$-vragen in de tragedie hebben meestal deze functie en toon.

33 Mijn analyse van 239-242 als insertie-expansies is alleen zinvol als 238 inderdaad geldt als 'vraag'. Die determinering is enigszins simplistisch, aangezien 238 ook een

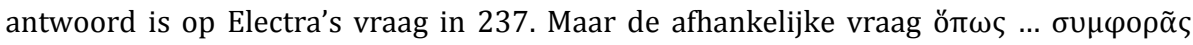

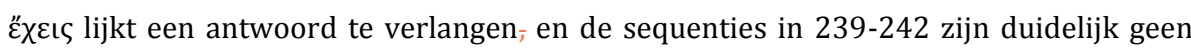
voortzetting van de eerdere vraag-antwoordsequenties, zodat de interpretatie als expansies verantwoord lijkt. 
Dat de vreemdeling met zijn vraag zelfs maar de mogelijkheid open laat dat Orestes bij terugkeer iets anders zou doen dan onmiddellijk overgaan tot vergelding, is voor Electra reden om de sequentiehet adjacency pair kortstondig open te breken en commentaar te leveren op het eerste paardeelfirst part (een soort van minimale insertie-expansieinsert expansion binnen haar eigen beurt). ${ }^{34}$ De gemarkeerde conversationele structuur, die gepaard gaat met een ongebruikelijke verdeling van één enkel vers in drie zinnen, is wederom een afspiegeling van een kortstondige flits van ergernis bij Electra. Die ergernis leidt ook tot een tijdelijke bekoeling van een (sinds 228) anderszins vriendelijk

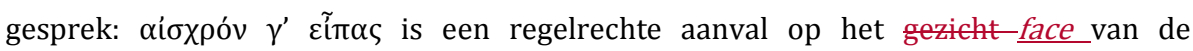
vreemdeling, zonder enige vorm van omhaal.

We kunnen deze opvallende verstoring van de interactionele structuur en het sociale equilibrium evenwicht opnieuw herleiden tot Electra's preoccupaties en karaktertrekken: Electra idealiseert Orestes als een glorieuze redder in nood, een 'verlosser van lasten' ( uitzichtloze situatie en die wraak kan nemen op de moeder en stiefvader die ze zo haat. Dat Orestes op een enige andere manier naar Argos zou kunnen terugkeren verwerpt Electra met nadruk, hier en elders in het stuk (zie 336-338, 524-526; in elk van deze passages is de dramatische ironie groot).

\section{Conclusie}

Leert de taalkunde ons iets over Electra, over de Electra, dat we anders niet zouden weten? Dat is misschien niet de juiste, of in ieder geval niet een helemaal eerlijke vraag. De taalkundige benaderingen die ik heb geïntroduceerd (en vele andere), kunnen ten hoogste een onderdeel vormen van de uitgebreide en gevarieerde gereedschapskist van

34 Electra's antwoord (het daadwerkelijke tweede paardeel) blijft impliciet, maar de

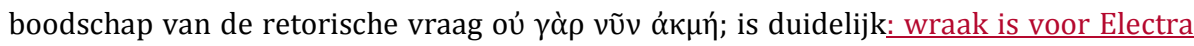
het enige legitieme antwoord. Orestes kan daardoor in zijn volgende beurt (276) overgaan naar een nieuw paar. 
de literatuurcriticus. Maar wie met dat gereedschap aan de gang gaat krijgt mogelijk wel met nieuwe helderheid inzicht in nuances die eerder vaag of onzichtbaar waren, en kan met meer precisie beschrijven hoe Euripides (of iedere andere toneelschrijver) zijn personages neerzet.

En hoe zit het met de gereedschapskist van de leerling op school? Naar mijn smaak lenen dit soort modellen zich uitstekend voor gebruik in de klas. Leerlingen kunnen aan de hand ervan inzicht krijgen in hun-eigen-hun eigen omgang met beleeflheid en 'gezicht'face en beleefdheid, en in de achterliggende structuren van hun eigen gesprekken, en ze kunnen worden uitgedaagd om die te confronteren met wat ze tegenkomen in de Griekse tragedie. $\underline{\text { Alleen al in de Electra zijn er, behalve de scènes die ik in dit artikel (slechts ten dele) heb }}$ besproken, talloze passages die leerlingen zouden kunnen benaderen vanuit de beleefdheidstheorie (bijvoorbeeld de andere interacties tussen Electra en haar echtgenoot in 341-363 en 405-431, de beruchte bespreking van de herkenningstekens door Electra en de oude man in 487-546, of de korte woordenwisseling tussen Electra en haar moeder voor de agōn-scène in 998-1010) en/of conversatieanalyse (de 'twijfelscène' vlak voor Clytaemestra's opkomst, 959-987, biedt bijvoorbeeld complex maar bijzonder rijk materiaal voor een analyse met deze methodologie). Als de tragische figuren en hun-dialogen-daarbij-door dergelijke oefeningen des tevoor leerlingen meer tot leven komen,, is dat helemaal des te meer mooi meegenomende moeite waard.

\section{Geciteerde werken}

Arnott, W.G. 1981. 'Double the Vision. A Reading of Euripides' Electra', Greece and Rome 28.2, 179-192.

Artz, R., A. van den Bergh en I.J.F. de Jong. 2016. Electra. Een tragedie van Euripides, Houten.

Bain, D. 1977. Actors and Audience. A Study of Asides and Related Conventions in Greek Drama, Oxford.

Barrios-Lech, P. 2016. Linguistic Interaction in Roman Comedy, Cambridge. 
Bonifazi, A., M. de Kreij \& A. Drummen. 2016. Particles in Ancient Greek Discourse. Five Volumes Exploring Particle Use Across Genres, Washington, DC.

Bousfield, D. 2008. Impoliteness in Interaction, Amsterdam.

Brown, H.P. 2006. 'Addressing Agamemnon: A Pilot Study of Politeness and Pragmatics in the Iliad, Transactions of the American Philological Association 136.1, 1-46.

Brown, P. en S.C. Levinson. 1978. 'Universals in Language Usage: Politeness Phenomena', in E. Goody (ed.), Questions and Politeness, Cambridge, 56-289.

Brown, P. en S.C. Levinson. 19872. Politeness: Some Universals in Language Use, Cambridge.

Catrambone, M. 2016. 'Off-Record Politeness in Sophocles. The Patterned Dialogues of Female Characters', Journal of Politeness Research 12.2, 173-195.

Conacher, D.J. 1967. Euripidean Drama, Toronto.

Cropp, M.J. (ed.). 1988. Euripides. Electra, Warminster.

Cropp, M.J. (ed.). 20132. Euripides. Electra, Oxford.

Culpeper, J. 2011. Impoliteness. Using Language to Cause Offence, Cambridge.

Denniston, J.D. (ed.). 1939. Euripides. Electra, Oxford.

Emde Boas, E.H. van. 2016. 'Signalementen. Euripides en zijn Electra', Lampas 49.2, 180186.

Emde Boas, E.H. van. Te verschijnen-2017a. 'Analyzing Agamemnon. Conversation Analysis and Particles in Greek Tragic Dialogue', Classical Philology.

Emde Boas, E.H. van. Te verschijnen-2017b. Language and Character in Euripides' Electra, Oxford.

Goffman, E. 1955. 'On Face Work: An Analysis of Ritual Elements in Social Interaction', Psychiatry 18, 213-31.

Grube, G. M. A. 1941. The Drama of Euripides, London.

Hall, J. 2009. Politeness and Politics in Cicero's Letters, Oxford.

Herman, V. 1995. Dramatic Discourse. Dialogue as Interaction in Plays, London.

Huls, E. 2001. Dilemma's in menselijke interactie, Utrecht.

Jefferson, G. 1992. Harvey Sacks. Lectures on Conversation, Oxford.

Kádár, D.Z. en\& M. Haugh. 2013. Understanding Politeness, Cambridge.

Kirchhoff, A. (ed.) 18672. Euripidis fabulae, vol. I. Berlin.

Kitto, H.D.F. 1961³. Greek Tragedy. A Literary Study, London.

Lardinois, A.P.M.H. 2017. 'Hoe je moeder te vermoorden? Psychologische manipulaties in de Electravan Euripides', Lampas 50, *****. 
Lloyd, M.A. 1986. 'Realism and Character in Euripides' Electra', Phoenix 40.1, 1-19.

Lloyd, M.A. 2004. 'The Politeness of Achilles. Off-Record Conversation Strategies in Homer and the Meaning of kertomia', Journal of Hellenic Studies 124, 75-89.

Lloyd, M.A. 2006. 'Sophocles in the Light of Face-Threat Politeness Theory', in I.J.F. de Jong en A. Rijksbaron (eds.), Sophocles and the Greek Language. Aspects of Diction, Syntax and Pragmatics, Leiden, 225-240

Lloyd, M.A. 2009. 'The Language of the Gods. Politeness in the Prologue of the Troades', in J.R.C. Cousland \& en J.R. Hume (eds:), The Play of Texts and Fragments. Essays in Honour of Martin Cropp, Leiden, 183-192.

Lloyd, M.A. 2013. 'Politeness/Impoliteness', in H.M. Roisman (ed.), Encyclopedia of Greek Tragedy, Chichester, 987.

Luschnig, C.A.E. 2013. 'Euripides: Electra', in in-H.M. Roisman (ed.), Encyclopedia of Greek Tragedy, Chichester, 378-384.

Mastronarde, D.J. 1979. Contact and Discontinuity. Some Conventions of Speech and Action on the Greek Tragic Stage, Berkeley.

Mazeland, H. 2003. Inleiding in de conversatieanalyse, Bussum.

Michelini, A.N. 1987. Euripides and the Tragic Tradition, Madison.

O’Brien, M.J. 1964. 'Orestes and the Gorgon. Euripides' Electra', American Journal of Philology 85.1, 13-39.

Ormand, K. 2009. 'Electra the Exile', in D. McCoskey \& en E. Zakin (eds:), Bound by the City. Greek Tragedy, Sexual Difference, and the Formation of the Polis, Albany, 247274.

Sacks, H., E.A. Schegloff \& en G. Jefferson. 1974. 'A Simplest Systematics for the Organization of Turn-Taking for Conversation', Language 50, 696-735.

Schegloff, E.A. 2007. Sequence Organization in Interaction. A Primer in Conversation Analysis I, Cambridge.

Schuren, L. 2014. Shared Storytelling in Euripidean Stichomythia, Leiden.

Schwinge, E.R. 1968. Die Verwendung der Stichomythie in den Dramen des Euripides, Heidelberg.

Scodel, R. 2008. Epic Facework. Self-Presentation and Social Interaction in Homer, Swansea.

Sidnell, J. en T. Stivers (eds:). 2012. The Handbook of Conversation Analysis, Chichester.

Slings, S.R. 1997. 'Adversative relators between PUSH and POP', in A. Rijksbaron 
Smith, D.L. 2012. The Rhetoric of Interruption. Speech-Making, Turn-Taking, and RuleBreaking in Luke-Acts and Ancient Greek Narrative, Berlin.

Steidle, W. 1968. Studien zum antiken Drama, München.

Stoessl, F. 1956. 'Die Elektra des Euripides', Rheinisches Museum 99, 47-92.

Swift, L. 2010. The Hidden Chorus. Echoes of Genre in Tragic Lyric, Oxford.

Verheij, H., H. Koning \& S. Veenman. 2016a. Euripides. Elektra. Leerlingenboek, Leeuwarden.

Verheij, H., H. Koning \& S. Veenman. 2016b. Euripides. Elektra. Docentenboek, Leeuwarden.

Watts, R.J. 2003. Politeness, Cambridge.

Wecklein, N. (ed.) 1898. Euripidis fabulae, vol. I.4: Elektra. Leipzig.

Wilamowitz, U. von 1883. 'Die beiden Elektren', Hermes 18, 214-263.

Yoon, F. 2012. The Use of Anonymous Characters in Greek Tragedy. The Shaping of Heroes, Leiden.

Zeitlin, F.I. 1970. 'The Argive Festival of Hera and Euripides' Electra', American Journal of Philology 101, 645-69. [Herdrukt in J. Mossman (ed.). 2003. Oxford Readings in Classical Studies. Euripides, Oxford, 261-284.] 